\title{
Unexpected Complexity of the $d m 1$ Mutation Revealed in the Structure of Three H-2D/L-Related Antigens
}

\author{
Pamela H. Wilson ${ }^{1}$, Roderick Nairn ${ }^{2 *}$, Stanley G. Nathenson ${ }^{2}$, \\ and Duane W. Sears ${ }^{1 \dagger}$ \\ ${ }^{1}$ Department of Biological Sciences, Section of Biochemistry and Molecular Biology, University of \\ California at Santa Barbara, Santa Barbara, California 93106 \\ ${ }^{2}$ Department of Microbiology and Immunology and the Department of Cell Biology, Albert Einstein \\ College of Medicine, Bronx, New York 10461
}

\begin{abstract}
The $\mathrm{H}-2 \mathrm{~L}^{\mathrm{dm} 1}$ and $\mathrm{H}-2 \mathrm{D}^{\mathrm{dm} 1}$ MHC antigens of the B10.D2 $\left(H-2^{d m 1}\right)$ mutant mouse strain (formerly known as M504 or $\mathrm{H}-2^{d a}$ ) have been compared to the $\mathrm{H}-2 \mathrm{~L}^{\mathrm{d}}$ and $\mathrm{H}-2 \mathrm{D}^{\mathrm{d}}$ antigens of the B10.D2 $\left(H-2^{d}\right)$ mouse strain. $\mathrm{L}^{\mathrm{dm} 1}$ and $\mathrm{L}^{\mathrm{d}}$ are $45000 \mathrm{M}_{\mathrm{r}}$ antigens and both are reactive with anti-H-2."28" ( $k / r$ anti- $\left.h 2\right)$ serum and unreactive with anti-H-2.4 ( $k / b$ anti- $a$ ) serum which detects private determinants of the $D^{d m 1}$ and $D^{d}$ antigens. However, the tryptic peptide compositions of these two antigens are different and, based on the number of major tryptic peptides which coelute during ion-exchange chromatography, the estimated peptide homology between $\mathrm{L}^{\mathrm{dml}}$ and $\mathrm{L}^{\mathrm{d}}$ is 80 percent. A newly defined antigen $\left(M_{r}=39000\right)$, designated gp $39^{\mathrm{dm} 1}$, was found in glycoprotein extracts of the $d m 1$ strain but not of the $d$ strain. This antigen coprecipitates with $\mathrm{L}^{\mathrm{dml}}$ but does not coprecipitate with $\mathrm{D}^{\mathrm{dml}}$ indicating that it lacks the $\mathrm{H}-2.4$ determinant. In comparison with $\mathrm{L}^{\mathrm{dm} 1}$, gp $39^{\mathrm{dml}}$ appears to contain far fewer Arg and Lys residues and is most likely not a simple proteolytic fragment of $L^{\mathrm{dm} 1}$. Finally, peptide maps of the $\mathrm{D}^{\mathrm{dm} 1}$ antigen show that the majority of its Arg peptides are identical to $\mathrm{D}^{\mathrm{d}}$ Arg peptides, whereas at least five of its Lys peptides and three of its Arg peptides correspond not to $\mathrm{D}^{\mathrm{d}}$ peptides but to $\mathrm{L}^{\mathrm{d}}$ and $\mathrm{L}^{\mathrm{dm} 1}$ peptides. These data raise the possibility that the $\mathrm{D}^{\mathrm{dm} 1}$ antigen is a hybrid molecule and they have also revealed an unexpected level of complexity in the $d m 1$ mutant phenotype.
\end{abstract}

\section{Introduction}

$\mathrm{H}-2 \mathrm{~L}$ antigens comprise a relatively newly defined class of cell-surface glycoproteins which appear to exhibit most, if not all of the structural, serological, and biological properties of the classical $\mathrm{H}-2 \mathrm{~K}$ and $\mathrm{H}-2 \mathrm{D}$ antigens encoded by the major

* Present address: Department of Microbiology and Immunology, University of Michigan Medical School, Ann Arbor, Michigan 48109.

$\uparrow$ To whom offprint reprint requests should be sent. 
histocompatibility complex (MHC) of the mouse (see reviews by Démant and Néauport-Sautês 1978, Levy and Hansen 1980). As directly inferred from tryptic peptide map comparisons (Sears and Polizzi 1980, Sears and Wilson 1981) and amino-acid sequence comparisons (Coligan et al. 1980), H-2L antigens are encoded by a genetic locus $(L)$ in the $\mathrm{MHC}$, which is distinct from the other MHC loci (i. e., $K$, $D, Q a$, and Tla) known to encode class I antigens (Klein 1979). By definition, class I antigens are approximately $45000 \mathrm{M}_{\mathrm{r}}$, membrane-integrated glycoproteins which are highly polymorphic in the species. They are also noncovalently associated with a smaller polypeptide, $\beta_{2}$-microglobulin $\left(\mathrm{M}_{\mathrm{r}}=11500\right)$, which shows a much more limited species polymorphism (Michaelson et al. 1980, Gates et al. 1981, Robinson et al. 1981).

One very informative approach to the study of the structure and function of $\mathrm{H}-2$ antigens has been to examine the properties of mutant mouse strains which have altered H-2 antigen structures (reviewed by Nairn et al. 1980b) and which, as a consequence, have altered biological properties (reviewed by Klein 1978). Detailed comparisons of the structures of mutant $\mathrm{H}-2$ antigens and their respective parental $\mathrm{H}-2$ antigens continue to provide valuable information concerning the genetic organization of the $\mathrm{MHC}$ and the various immunological properties of $\mathrm{H}-2$ antigens themselves.

In the present study, the biochemical properties and tryptic peptide composition of $\mathrm{L}^{\mathrm{dm} 1}$ are compared with those properties of $\mathrm{L}^{\mathrm{d}}$ which have previously been characterized by Sears and co-workers (1980). The $d m 1$ mutant mouse strain was originally derived from a mouse treated with the alkylating agent, diethyl sulfate (Egorov 1967). The $\mathrm{L}^{\mathrm{dm} 1}$ antigens and the $\mathrm{D}^{\mathrm{dm} 1}$ antigen of this mutant have been shown to be structurally and functionally different from the parental antigens in studies of their serological properties, cell-surface redistribution characteristics, and ability to complement in skin grafting tests (Morgan et al. 1978, Iványi and Démant 1979, Huang et al. 1979). Moreover, an earlier comparative tryptic peptide map study by Brown and co-workers (1978) of the $D^{\mathrm{dm} 1}$ antigen of this mutant showed that its tryptic peptide homology with the parental $\mathrm{D}^{\mathrm{d}}$ antigen is only 70 percent, an observation which contrasts with the much higher degrees of tryptic peptide homology (more than 90 percent) generally observed between the $\mathrm{K}^{\mathrm{b}}$ antigen and several of its spontaneously derived structural mutants (as reviewed by Nairn et al. 1980b). Reexamination of the tryptic peptide structure of $D^{\mathrm{dm} 1}$ in the present study revealed a striking and unexpected homology with the $\mathrm{L}^{d}$ and $\mathrm{L}^{\mathrm{dm} 1}$ antigens. Also discovered, and partially characterized, in the course of this investigation was an antigen, $\mathrm{gp} 39^{\mathrm{dm} 1}\left(\mathrm{M}_{\mathrm{r}}=39000\right)$, which is present in $d m l$ but not in $d$ extracts. Collectively, our results raise intriguing questions as to the genetic control and expression of MHC antigens in the $d m 1$ mutant.

\section{Materials and Methods}

Antisera. Antisera were raised in the following standard combination: anti-H-2.27, 28, 29 (abbreviated anti-H-2. "28"): $k / r$ anti- $h 2$, which is analogous to the NIH antiserum, D28b; and anti-H-2.4: $k / b$ anti- $a$.

Mice. B10.D2 $\left(H-2 D^{a m 1}\right)$ mice were maintained by Ms. Harriel Martinez in Dr. Frank Lilly's laboratory at the Albert Einstein College of Medicine, New York. B10.D2/nSnJ $\left(H-2^{d}\right)$ mice were obtained from Jackson Laboratories. 
Radiolabeling of spleen cells. Radioactive amino acids from New England Nuclear were incorporated into spleen cells by a modification (R. Nairn, S. Schumacher, and S. G. Nathenson, manuscript in preparation) of the radiolabeling method described for cell lines by Nairn and co-workers (1980a).

Isolation and tryptic peptide map analysis of $H-2 L$ antigens. The procedures of Brown and co-workers (1974) were employed for isolating H-2 antigens and analyzing their tryptic peptides. In summary, NP-40 lysates of radiolabeled spleen cells were chromatographed on Lens culinaris hemagglutanin Sepharose columns and the glycoprotein fractions were isolated by elution with $\alpha$-methyl-D-mannoside. Glycoprotein pools were precleared of the $\mathrm{D}^{\mathrm{dm} 1}$ or $\mathrm{D}^{\mathrm{d}}$ antigen by one or two additions of $k / b$ anti- $a$ followed each time by goat anti-mouse $\operatorname{Ig}(G A M I g)$; these precipitates were used for $\mathrm{D}^{\mathrm{dm} 1}$ or $\mathrm{D}^{\mathrm{d}}$ peptide map analysis. The preclearing step was essential because $D^{d}$ (Sears and Wilson 1982), and most probably $D^{d n 11}$ (Iványi and Démant 1979) cross-react with $k / r$ anti- $h 2$. In some cases the glycoprotein fractions were also preclared with Swiss Webster (Simonsen Laboratories, Inc.) normal mouse sera to remove nonspecifically precipitating proteins as described by Sears and co-workers (1980). After anti-H-2.4 preclearing, the $\mathrm{L}^{\mathrm{d}}$ or $\mathrm{L}^{\mathrm{dm}}{ }_{1}$ antigens were isolated by immunoprecipitation with $k / r$ anti- $h 2$ and GAMIg.

${ }^{3} \mathrm{H}$-labeled and ${ }^{14} \mathrm{C}$-labeled immunoprecipitates were mixed, dissolved in SDS, reduced, alkylated, and prepared for gel filtration chromatography on Bio-Gel A-1.5m (Bio-Rad Laboratories) in $50 \mathrm{mM}$ Tris- $\mathrm{HCl}, 0.5 \%$ (w/v) SDS, $1 \mathrm{mM}$ DTT, $\mathrm{pH} 7.5$. The $45000 \mathrm{~mol}$. wt. fraction from the column was rechromatographed to improve resolution and a second, narrower pool was precipitated with $15 \% \mathrm{TCA}$ before digestion with TPCK-trypsin. The acid-soluble peptides were fractionated by cation-exchange chromatography. Peptides eluted by a linear acetate/pyridine $\mathrm{pH}$ gradient were dried and counted in Aquasol. Two sets of 5 or 10 min counts were averaged and corrected for isotope spills in constructing the final maps.

SDS polyacrylamide gel electrophoresis. Immunoprecipitates of $\mathrm{H}-2 \mathrm{~L}$ antigens - isolated from $\mathrm{H}-2 \mathrm{D}$ precleared glycoprotein extracts using anti-H-2."28" and Staphylococcus aureus Cowan I (Cullen and Schwartz 1976)-were boiled in SDS, reduced with 2-mercaptoethanol and electrophoresed in 4/10\% discontinuous polyacrylamide gels as described by Laemmli and Favre (1973) with the modifications of Cullen and co-workers (1976). Two-millimeter slices of the gels were counted as described by Sears and Polizzi (1980). In one set of studies designed to compare the tryptic peptide maps of $L^{\mathrm{dm} 1}$ with the coimmunoprecipitating gp $39^{\mathrm{dm} 1}$ glycoprotein, the $30-50000 \mathrm{M}_{\mathrm{r}}$ pool from the SDS gel filtration step was further fractionated by electrophoresis in $4 / 10 \%$ gels. The gels were sliced, ground, and eluted into 5 $\mathrm{mM}$ Tris- $\mathrm{HCl}, 0.05 \%$ (w/v) SDS, $0.01 \mathrm{mM} \mathrm{DTT}, \mathrm{pH} 7.5$. The resolved $\mathrm{L}^{\mathrm{dm}_{1}}$ and $\mathrm{gp} 39^{\mathrm{dm}_{1}}$ components were separately precipitated with TCA for tryptic peptide map analysis.

\section{Results}

Biochemical and serological properties of $L^{d m 1}$ and $g p 39^{d m 1}$. As determined by polyacrylamide gel electrophoresis and gel filtration in SDS, the anti-H-2."28" serum in this study precipitates 45000,39000 , and $12000 \mathrm{M}_{\mathrm{r}}$ molecules from $d m 1$ glycoprotein extracts (Fig. 1A). In contrast, the antiserum yields only 45000 and $12000 \mathrm{M}_{\mathrm{r}}$ proteins from $d$ extracts (Fig. 1B). The $45000 \mathrm{M}_{\mathrm{r}}$ molecule is $\mathrm{L}^{\mathrm{dm} 1}$ as judged by its serological and tryptic peptide (see below) homologies to the previously characterized $L^{d}$ molecule (Sears and Polizzi 1980, Sears et al. 1980). The $12000 \mathrm{M}_{\mathrm{r}}$ protein in the $d m 1$ extract precipitates is most likely $\beta_{2}$-microglobulin, a noncovalently bound subunit common to H-2 antigens (Natori et al. 1974) including the $\mathrm{H}-2 \mathrm{~L}^{\mathrm{d}}$ antigen (Coligan et al. 1980, D. W. Sears, unpublished data). The $39000 \mathrm{M}_{\mathrm{r}}$ molecule is tentatively assumed to be a glycoprotein, since it was recovered from the fraction adsorbed to Lens culinaris hemagglutinin columns, and it is therefore designated $\mathrm{gp} 39^{\mathrm{dm} 1}$. In comparison with $\mathrm{L}^{\mathrm{dm} 1}$, gp $39^{\mathrm{dm} 1}$ contains approximately half the number of Arg residues (extrapolation from Fig. 4) and far fewer Lys residues as it was barely evident in SDS-dissociated anti-H-2."28" 


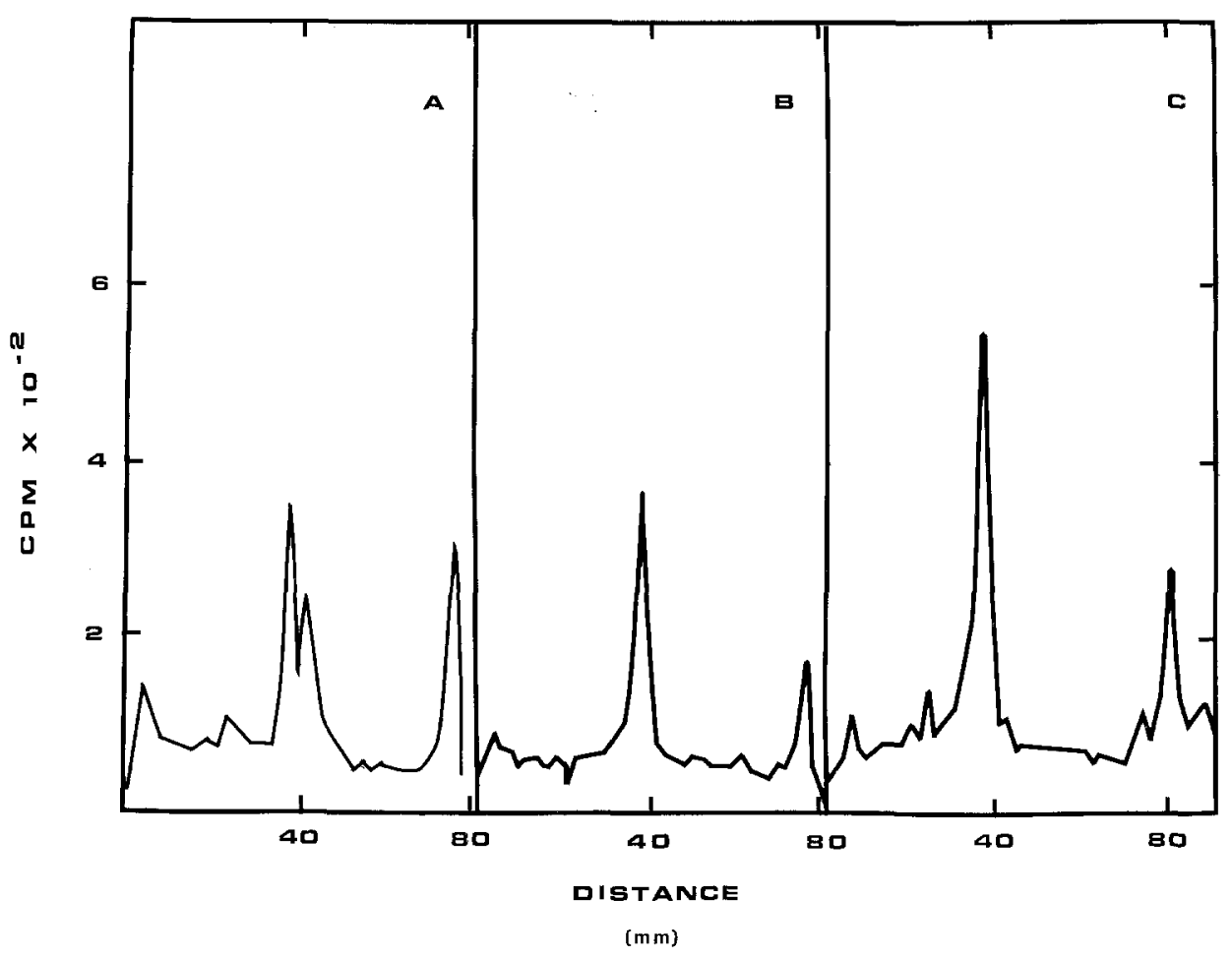

Fig. 1 A-C. SDS polyacrylamide gels of immunoprecipitates of lentil lectin purified glycoprotein extracts of $d m 1$ and B10.D2 splenocytes. (A) Anti-H-2." 28 " immunoprecipitate of a ${ }^{3} \mathrm{H}-\mathrm{Arg}-\mathrm{labeled} d m 1$ glycoprotein extract showing major peaks of $\mathrm{M}_{\mathrm{r}} 45000,39000$, and 12000 (at 38, 42, and $75 \mathrm{~mm}$, respectively) as determined by migration distances relative to immunoglobulin heavy and light chain standards. (B) Anti-H-2." 28 " immunoprecipitate of a ${ }^{3} \mathrm{H}$-Arg-labeled B10.D2 glycoprotein extract showing only peaks $45000 \mathrm{M}_{\mathrm{r}}$ and $12000 \mathrm{M}_{\mathrm{r}}$ (C)Anti-H-2."28" immunoprecipitate of a ${ }^{3} \mathrm{H}$-Lys-labeled glycoprotein extract of $d m 1$ showing peaks of $45000 \mathrm{M}_{\mathrm{x}}$ and $12000 \mathrm{M}_{\mathrm{r}}$ only.

immunoprecipitates of Lys-labeled $d m 1$ extracts either electrophoresed on polyacrylamide gels (Fig. 1C) or chromatographed by gel filtration (data not shown). It is not known whether $\mathrm{gp} 39^{\mathrm{dm} 1}$ is associated with $\mathrm{L}^{\mathrm{dm} 1}, \beta_{2} \mathrm{~m}$ or is membrane integrated. gp39 ${ }^{\mathrm{dm} 1}$ does not share the H-2.4 determinant with $\mathrm{D}^{\mathrm{dm} 1}$ since it did not coprecipitate with this antigen in anti-H-2.4 immunoprecipitates.

Tryptic peptide map comparisons between $L^{d m 1}$ and $L^{d}$. Paired-label tryptic peptide maps of $\mathrm{L}^{\mathrm{dm} 1}$ and $\mathrm{L}^{\mathrm{d}}$, metabolically labeled with either Lys or Arg, were analyzed to determine peptide differences between the two antigens. As shown in Figure 2, five major Lys peptides from each of the molecules coelute from the ion-exchange column, indicating that approximately 77 percent of the major Lys peptides of the two antigens are homologous (see also Table 1). Several minor Lys-peptide peaks also appear to be shared by the two antigens (Fig. 2) although there are a number of minor peak differences, some of which could represent real differences between the molecules and others which may derive from gp $39^{\mathrm{dm} 1}$ as discussed below. The 


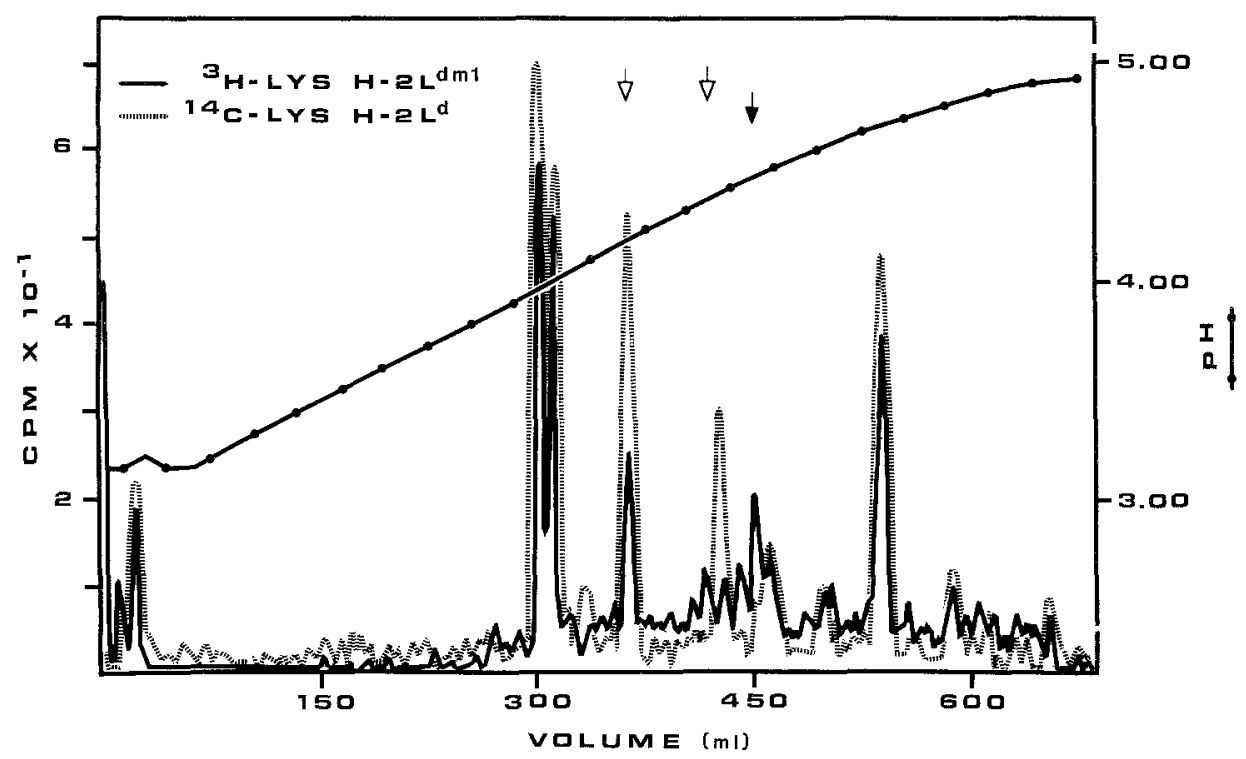

Fig. 2. Tryptic peptide map of ${ }^{3} \mathrm{H}$-Lys-labeled $\mathrm{L}^{\mathrm{dm} 1}(-)$ vs. ${ }^{14} \mathrm{C}$-Lys-labeled $\mathrm{L}^{\mathrm{d}}$ (----). The cochromatographed H-2L antigens from anti-H-2.28 immunoprecipitates of Lys-labeled $d m 1$ and $d$ extracts were digested with trypsin and the peptides fractionated by ion-exchange chromatography using a pyridine/acetate $\mathrm{pH}$ gradient (-_- Open arrows designate locations of major unique $\mathrm{L}^{\mathrm{d}}$ peptide peaks while a closed arrow designates the position of a major unique $\mathrm{L}^{\mathrm{dm} 1}$ peptide peak.

Table 1. Tryptic peptide homologies between $\mathrm{L}^{\mathrm{dm} 1}, \mathrm{~L}^{\mathrm{d}}$, and $\mathrm{gp} 39^{\mathrm{dm} 1}$

\begin{tabular}{|c|c|c|c|c|c|}
\hline \multirow{2}{*}{$\begin{array}{l}\text { Labeled } \\
\text { amino acid }\end{array}$} & \multicolumn{3}{|c|}{ No. of major peaks* } & \multicolumn{2}{|c|}{ Coincident major peaks $(\%)$} \\
\hline & $\mathrm{H}-2 \mathrm{~L}^{\mathrm{d}}$ & $\mathrm{H}-2 \mathrm{~L}^{\mathrm{dm} 1}$ & $\mathrm{gp} 39^{\mathrm{din} 1}$ & $\mathrm{~L}^{\mathrm{dm} 1}: \mathrm{L}^{\mathrm{d}}$ & $\mathrm{L}^{\mathrm{dm} 1}: \mathrm{gp} 39^{\mathrm{dm} 1 \neq}$ \\
\hline Arg & 11 & 16 & 11 & 82 & 72 \\
\hline Lys $^{\dagger}$ & 7 & 6 & ND & 77 & - \\
\hline Arg + Lys & 18 & 22 & & 80 & \\
\hline
\end{tabular}

* A "major" peak is arbitrarily considered to be one which has a level of radioactivity exceeding ca. 22 percent of the cpm present in the largest peak for that isotope. The peaks representing nonadsorbed peptides at the beginning of $\mathrm{pH}$ gradients are not considered in these comparisons. Several limitations of such homology estimates have been discussed previously in footnote 7 of Sears et al. (1980) and by Brown and co-workers (1974).

+ In Figure 2, it is assumed that there are two $\mathrm{L}^{\mathrm{d}}$ peptides at approximately $360 \mathrm{ml}$ and only one coincident $\mathrm{L}^{d \mathrm{~m}_{1}}$ peptide at this location because the otherwise constant ${ }^{14} \mathrm{C} /{ }^{3} \mathrm{H} \mathrm{cpm}$ ratio for the coincident major peaks exactly doubles here.

* Percentage of gp $39^{\mathrm{dm} 1}$ peaks coincident with $\mathrm{L}^{\mathrm{dm} \mathrm{t}}$ peaks.

paired-label Arg-peptide map comparing $L^{\mathrm{dm} 1}$ and $\mathrm{L}^{\mathrm{d}}$ is shown in Figure 3. When compared with the number of major Lys-peptide peaks, there are about twice as many major Arg-peptide peaks and, of these, four appear to be unique to $L^{\mathrm{dm} 1}$, whereas none is unique to $\mathrm{L}^{\mathrm{d}}$. The major Arg-peptide homology is found to be 


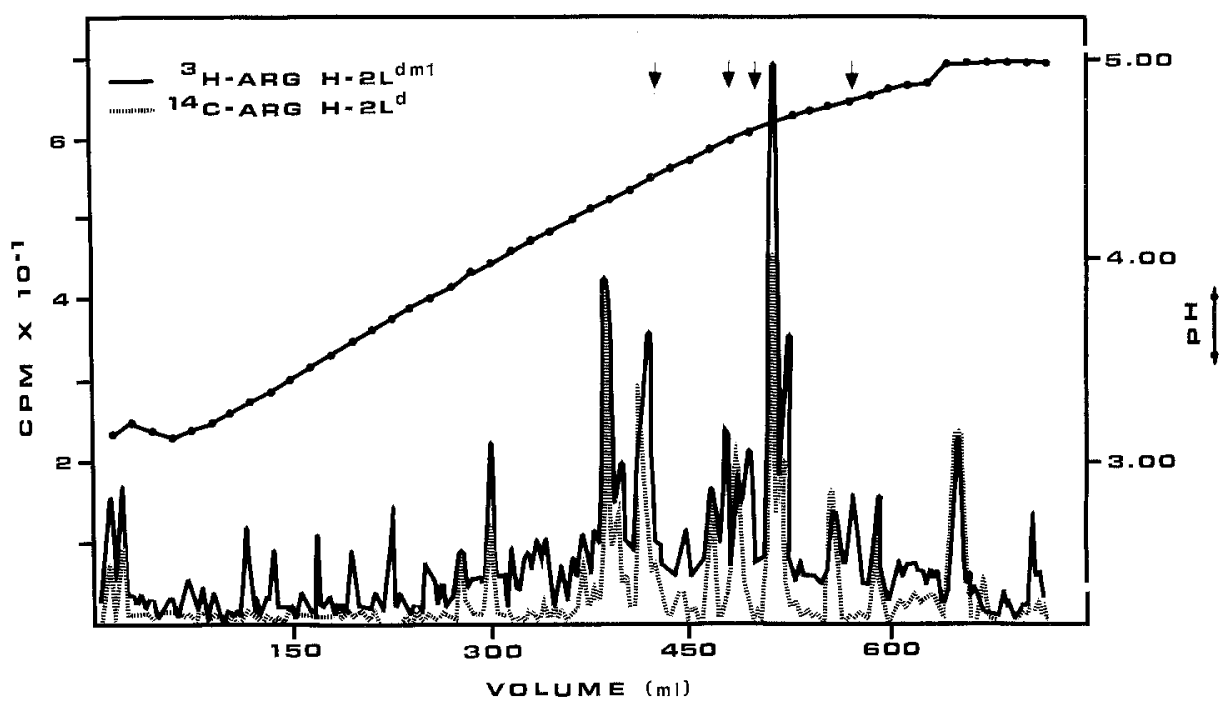

Fig. 3. Tryptic peptide map of ${ }^{3} \mathrm{H}$-Arg-labeled $\mathrm{L}^{\mathrm{dm} 1}$ (__-) and ${ }^{14} \mathrm{C}-\mathrm{Arg}$-labeled $\mathrm{L}^{\mathrm{d}}\left({ }_{--}-{ }_{-}\right.$isolated as described in the legend to Figure 2 . The closed arrows designate a major unique $L^{\mathrm{dm}}$ peptide peak; no major unique $\mathrm{L}^{\mathrm{d}}$ Arg-peptide peak was clearly evident although such might exist in the map.

approximately 82 percent (Table 1). Again, there are many more minor Arg peptides in the $\mathrm{L}^{\mathrm{dm} 1}$ map than in the $\mathrm{L}^{\mathrm{d}}$ map and the minor peak heterogeneity was found to correlate, as in the case of the Lys maps, with the size of the SDS gel filtration pools preceding the peptide maps and, therefore, with the amount of contamination by the gp $39^{\mathrm{dm} 1}$ antigen; in other Arg-L ${ }^{\mathrm{dm} 1}$ single-label maps (not shown) where the gel filtration pools were relatively very narrow, fewer minor peaks were observed. The overall tryptic peptide homology determined from the combined numbers of major Lys- and Arg-peptide peaks in Figures 2 and 3 is approximately 80 percent (Table 1).

Tryptic peptide map comparison of $L^{d m 1}$ and $g p 39^{d m 1}$. In Figure 4, the Arg tryptic peptides of $\mathrm{L}^{\mathrm{dm} 1}$ are compared with those of $\mathrm{gp} 39^{\mathrm{dm} 1}$ after these two coprecipitating molecules were separated by SDS gel filtration followed by SDS polyacrylamide gel electrophoresis. The latter step greatly improved the resolution between these molecules. The direct comparison between the two single-label maps in Figure 4 is judged to be an accurate one because (1) both antigens were treated identically during the purification and peptide mapping procedures; (2) both spent equal times in the SDS-containing buffers which are known to potentiate Met oxidation and thereby cause peptide charge heterogeneity (S. G. Nathenson and colleagues, unpublished observations); and (3) the $\mathrm{L}^{\mathrm{dm} 1}$ map resembles other $\mathrm{L}^{\mathrm{dm} 1}$ maps. By way of comparison, eight major and minor peptide peaks from gp $39^{\mathrm{dm} 1}$ are coincident with and in the same proportion as $\mathrm{L}^{\mathrm{dm} 1}$ Arg-peaks. Two major and one intermediate peptide peak in the gp $39^{\mathrm{dm} 1}$ map do not show corresponding peaks of the same relative proportions in the $\mathrm{L}^{\mathrm{dm} 1}$ map. Also, ten major and minor peaks in the $L^{\mathrm{dm} 1}$ map appear to lack corresponding peaks in the $\mathrm{gp} 39^{\mathrm{dm} 1}$ map. Because these molecules are unequal in molecular weight, a homology comparison calculated like 


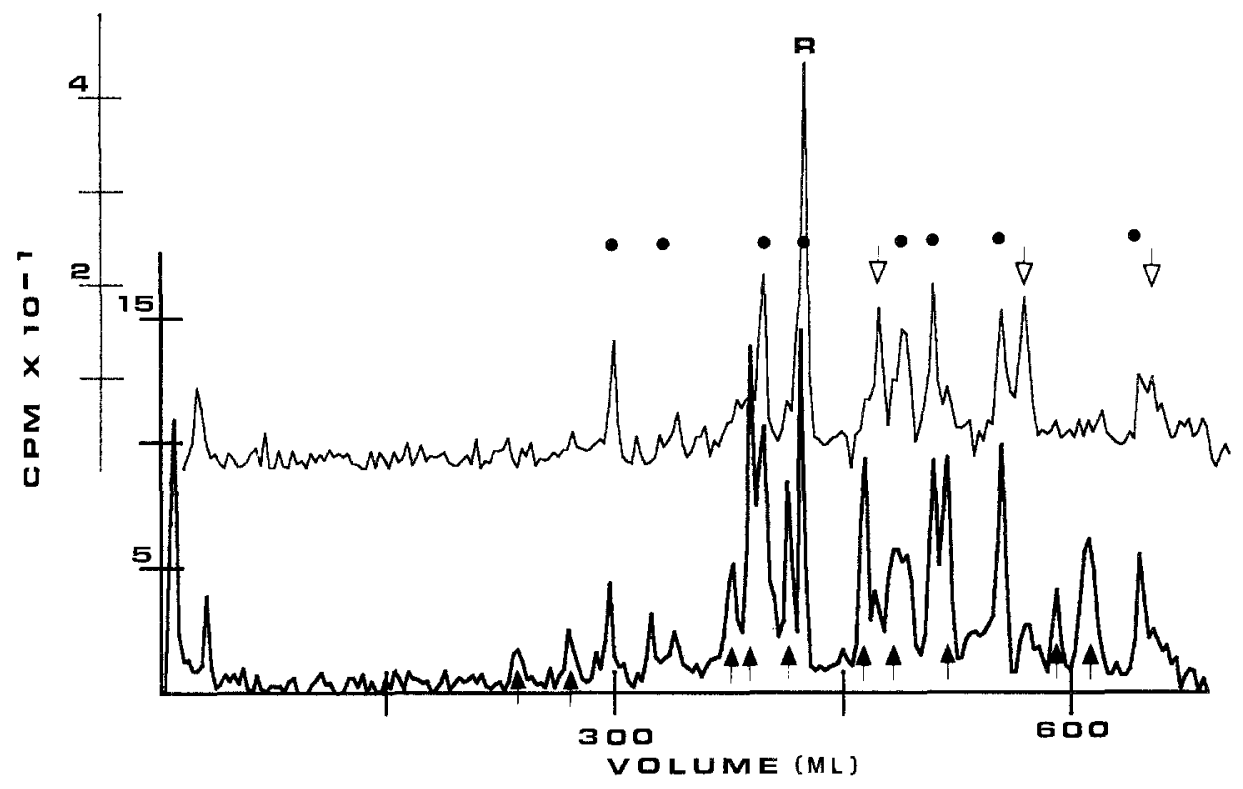

Fig. 4. Tryptic peptide map comparison between ${ }^{3} \mathrm{H}$-Arg-labeled gp $39^{\mathrm{dm}} 1$ and $\mathrm{L}{ }^{\mathrm{dm} !}$. These two molecules, isolated by anti-H-2. "28" immunoprecipitation of anti-H-2.4 precleared glycoprotein extracts, were separated by a combination of gel filtration chromatography in SDS and gel electrophoresis in SDS. They were treated identically throughout the purification procedure and mapped within a few days of each other using different aliquots of the same stock solution of the $\mathrm{pH}$-gradient buffers. Free ${ }^{14} \mathrm{C}$-Arg was included in both samples as a position marker and in both maps the percentage isotope distribution in the coincident peaks labeled $\mathrm{R}$ is 60 percent ${ }^{14} \mathrm{C}$ and 40 percent ${ }^{3} \mathrm{H}$. The $\mathrm{R}$ peaks and the other peaks in the two maps were brought into almost complete alignment by shifting the upper map four fractions $(12 \mathrm{ml})$ to the right. The upper map is of ${ }^{3} \mathrm{H}$-Arg-gp $39^{\mathrm{dm}} 1$ and the lower map is of ${ }^{3} \mathrm{H}-$ Arg- $\mathrm{L}^{\mathrm{dm} 1}$. Open arrows designate major peaks of $\mathrm{gp} 39^{\mathrm{dm} 1}$ not coincident with $\mathrm{L}^{\mathrm{dm} 1}$ peaks while solid arrows designate the peaks of $L^{\mathrm{dm} 1}$ not coincident with gp $39^{\mathrm{dm} 1}$ peaks. The remaining peaks indicated with dots are coincident and in the same relative proportions in the two maps.

those above would be ambiguous. Therefore, the homology was estimated by dividing the number of $g p 39^{\mathrm{dm} 1}$ peaks shared with $\mathrm{L}^{\mathrm{dm} 1}$ by the total number of gp $39^{\mathrm{dm} 1}$ peaks. Thus, if gp $39^{\mathrm{dm} 1}$ were a simple proteolytic breakdown product of $\mathrm{L}^{\mathrm{dm} 1}$, one would expect to find the homology determined in this way to be either 91 or 100 percent depending on whether or not the site of cleavage gave rise to a new Arg-peptide peak. However, the homology observed here is 72 percent (Table 1). The identification of the major and most of the minor peptide differences between $\mathrm{L}^{\mathrm{dm} 1}$ and gp39 ${ }^{\mathrm{dm} 1}$, as shown in Figure 4, was confirmed by a second set of peptide maps (not shown) which were independently derived from a different ${ }^{3} \mathrm{H}$-ArgB.10.D2 $\left(H-2^{d m 1}\right)$ glycoprotein extract using the same separation procedures described above and in the legend to Figure 4.

Tryptic peptide analysis of $D^{d m 1}$ in relation to $L^{d}, L^{d m 1}$, and $D^{d}$. Portions of several paired-label tryptic peptide maps spanning identical $\mathrm{pH}$ ranges are aligned in Figures 5 and 6 to better compare the structures of these four antigens. Identical 
peaks in adjacent maps of the same antigen are connected by lines in these figures. The lack of absolute vertical alignment throughout the maps is due to slight variations in the $\mathrm{pH}$ gradients, which, it should be noted, are extremely shallow, increasing only approximately $0.003 \mathrm{pH}$ units $/ \mathrm{ml}$ in the midportions of these maps. Thus, small but noticeable shifts in peak positions frequently occur.

Lys-peptide elution profiles between $\mathrm{pH} 3.90-4.85$ are shown in Fig. 5A-5C. This $\mathrm{pH}$ range includes over 80 percent of the Lys peptides of the four antigens compared. $\mathrm{D}^{\mathrm{dm} 1}$ appears to share at least five Lys peptides (Fig. 5A, peaks 1-5) with both $\mathrm{L}^{\mathrm{dm} 1}$ (Fig. 5B) and $\mathrm{L}^{\mathrm{d}}$ (Fig. 5A) while, in contrast, $\mathrm{D}^{\mathrm{d}}$ shares only one Lys peptide with $\mathrm{L}^{\mathrm{dm} 1}$ (Fig. 5C, peak 3 ) and $\mathrm{L}^{\mathrm{d}}$ (as shown previously by Sears et al. 1980). Not only are the $\mathrm{D}^{\mathrm{dm} 1}, \mathrm{~L}^{\mathrm{d}}$, and $\mathrm{L}^{\mathrm{dm} 1}$ peaks coincident in position but their relative proportions are also in strikingly close agreement. Peaks 1 and 2 are particularly notable in this respect because they are characteristic of the Lys peptide profiles of $\mathrm{L}^{\mathrm{d}}$ as shown previously by Sears and co-workers $(1980) . \mathrm{L}^{\mathrm{d}}, \mathrm{L}^{\mathrm{dm} 1}$, and $\mathrm{D}^{\mathrm{dm} 1}$ all uniformly show this doublet, the peaks of which are separated by only $0.03-0.05 \mathrm{pH}$ units, or just one $3 \mathrm{ml}$ fraction out of a total elution volume of $690 \mathrm{ml}$. Moreover, the first peak uniformly appears in just one fraction volume while the second peak appears almost entirely in two fraction volumes. A closer inspection of the fine structure of these maps reveals some peak variation in maps obtained in different experiments (cf. $\mathrm{L}^{\mathrm{dm} 1}$ in Figs. $5 \mathrm{~B}$ and $5 \mathrm{C}$ ) and this probably is a result, in part at least, of the SDS gel filtration pool sizes and/or differential Met oxidation as discussed above.

The Arg-peptide profile comparisons between $\mathrm{D}^{\mathrm{dm} 1}, \mathrm{D}^{\mathrm{d}}, \mathrm{L}^{\mathrm{d}}$, and $\mathrm{L}^{\mathrm{dm} 1}$ are shown in Figure 6 for the pH range 3.70-4.75. In these comparisons, $\mathrm{D}^{\mathrm{dm} 1}$ is found to have the greatest homology with $\mathrm{D}^{\mathrm{d}}$ (Fig. $6 \mathrm{C}$ ): $\mathrm{D}^{\mathrm{dm} 1}$ appears to have lost just one major peptide and to have gained one major, one intermediate, and one minor Arg peptide relative to $\mathrm{D}^{\mathrm{d}}$, there being an overall Arg peptide homology of 86 percent between the two molecules. These results are in basic agreement with those of Brown and coworkers (1978) who also showed (using the same procedures but a different ionexchange resin) that the Arg peptide profiles of $D^{d m 1}$ and $D^{d}$ are very similar while the Lys peptide profiles are very dissimilar. The additional observation made in the present study is that the three additional Arg peptides found in the $\mathrm{D}^{\mathrm{dm} 1}$ map appear to correspond to peptides in the $\mathrm{L}^{\mathrm{d}}$ and $\mathrm{L}^{\mathrm{dm} 1}$ maps (Fig. 6, peaks 1, 2, and 3). Thus, as with the Lys peptides of $D^{\mathrm{dm} 1}$, certain Arg peptides also appear to derive from $\mathrm{L}^{\mathrm{d}}$ and are shared with $L^{\mathrm{dm} 1}$. As was found to be the case with the Lys peptide maps of $\mathrm{L}^{\mathrm{d}}$, some variation is found between the $\operatorname{Arg} \mathrm{L}^{\mathrm{d}}$ maps. This is particularly notable in the region of the gradient between $300-450 \mathrm{ml}$, where two major peptide peaks are present in one map (Fig. 6A) and virtually absent in another (Fig. 6B). This variation has been observed previously (cf. Sears and Polizzi 1980 with Sears et al. 1980) and may indicate that these peptides are marginally soluble under these experimental conditions. One other notable variation occurs around peak 3 in Figure 6 . The major peptide peak of $\mathrm{L}^{\mathrm{d}}$ always occurs in this region and it appears that slight variations in the very shallow $\mathrm{pH}$ gradient (here less than $0.003 \mathrm{pH}$ units $/ \mathrm{ml}$ ) can lead to variable positioning of more than one tryptic peptide. Nevertheless, a peak corresponding exactly to the peak 3 of $\mathrm{D}^{\mathrm{dm} 1}$ (Fig. $6 \mathrm{~B}$ and $\mathrm{C}$ ) is always found. 


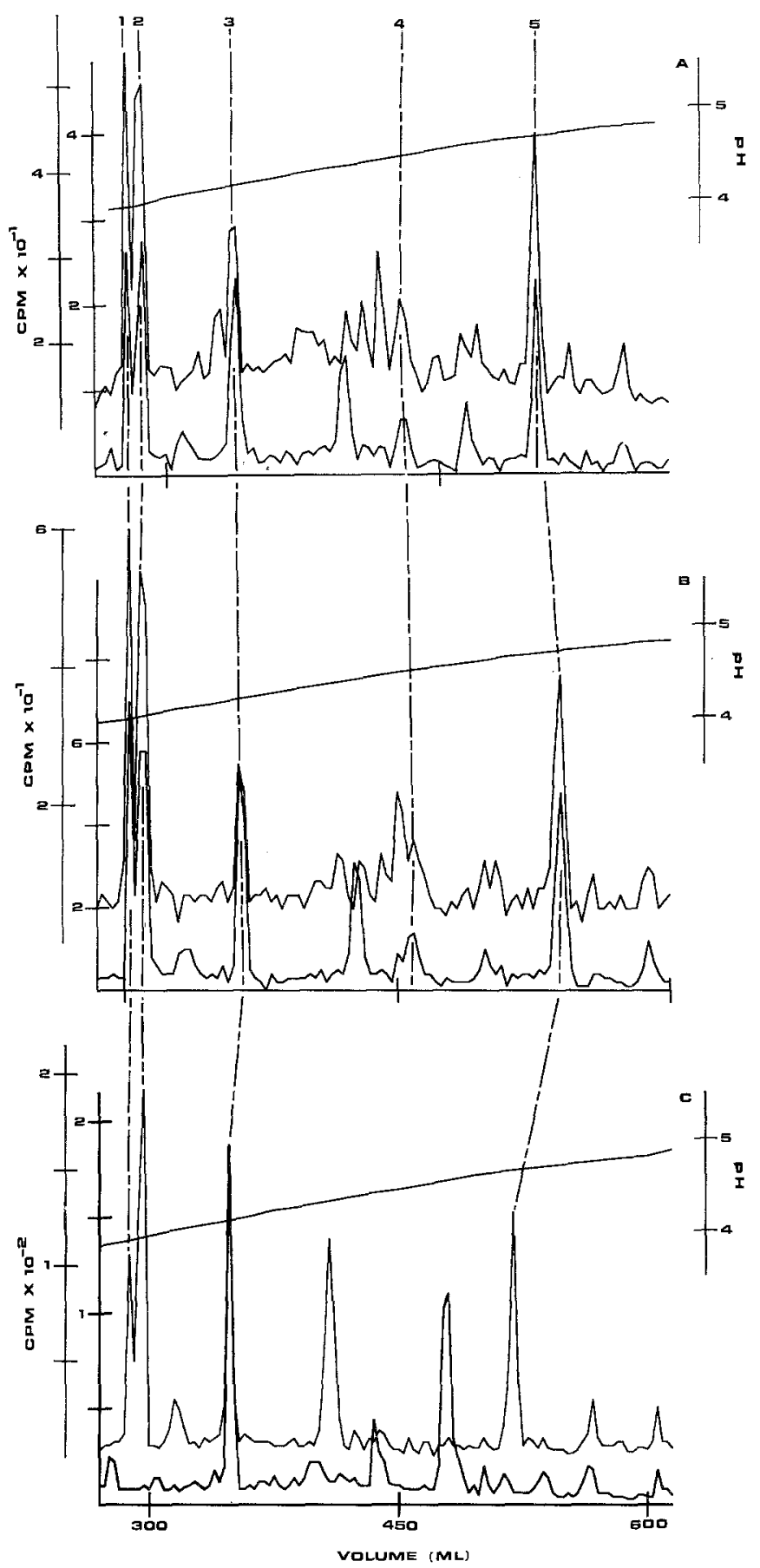

Fig. 5 (A-C). Portions of three paired-label Lys-tryptic peptide maps are aligned to illustrate homologous peaks between them, as designated by dashed lines 1-5. For purposes of clarification one map within each panel has been shifted vertically and, to optimize alignment, the panels have been shifted horizontally. The $\mathrm{pH}$ gradient for each panel is indicated at the right. Because adjacent panels show peptide maps of a common antigen, it is possible to align homologous peaks as indicated by the dashed lines connecting panels. The lack of complete vertical alignment results from the shallowness of the $\mathrm{pH}$ gradient. (A) Upper map, ${ }^{3} \mathrm{H}-\mathrm{L} y \mathrm{~s}-\mathrm{D}^{\mathrm{dm} 1}$; lower map, ${ }^{14} \mathrm{C}-\mathrm{L}$ ys- $\mathrm{L}^{\mathrm{d}}$. (B) Upper map, ${ }^{3} \mathrm{H}$-Lys- $\mathrm{L}^{\mathrm{dm} 1}$; lower map, ${ }^{14} \mathrm{C}$-Lys-L . (C) Upper map, ${ }^{3} \mathrm{H}$-Lys-L ${ }^{\mathrm{dm}{ }_{1}}$; lower map, ${ }^{14} \mathrm{C}$-Lys-D ${ }^{\mathrm{d}}$ (isolated from RADA1 $\left(H-2^{2}\right)$ tumor cells). 


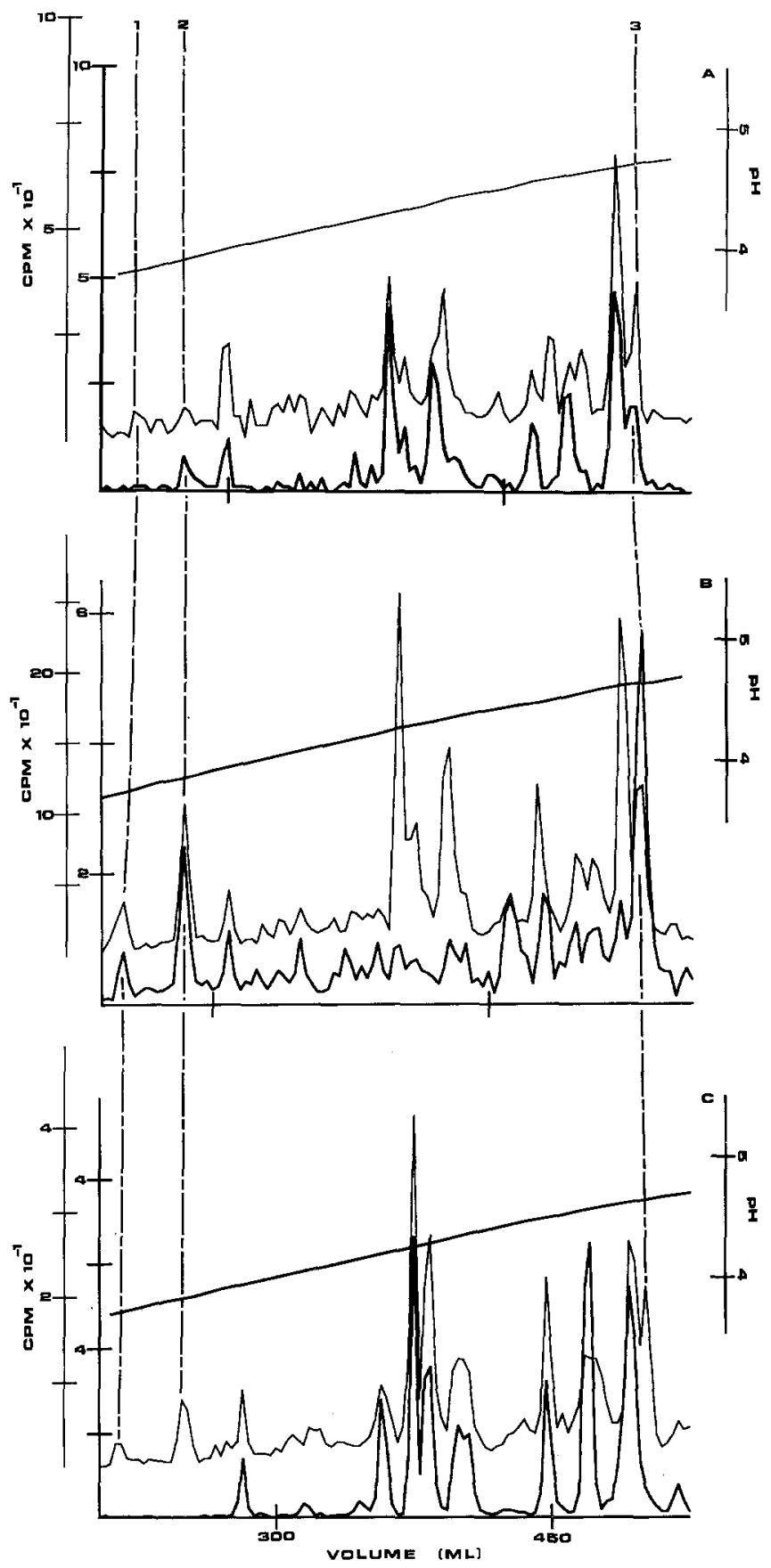

Fig. 6 (A-C). Portions of three paired-label Arg-tryptic peptide maps were aligned to illustrate homologous peaks between them, as designated by dashed lines 1-3. Again, for purposes of clarification one map within each panel has been shifted vertically, and to optimize alignment, the panels have been shifted horizontally. The $\mathrm{pH}$ gradient for each panel is indicated at the right and peak alignment is determined as described in the legend to Figure 5. (A) Upper map, ${ }^{3} \mathrm{H}-\mathrm{Arg}-\mathrm{L}{ }^{\mathrm{dm}}{ }_{1}$; lower map, ${ }^{14} \mathrm{C}-\mathrm{Arg}-\mathrm{L}{ }^{\mathrm{d}}$. (B) Upper map, ${ }^{3} \mathrm{H}$-Arg-D ${ }^{\mathrm{dm}}$; lower map, ${ }^{14} \mathrm{C}$-Arg-L ${ }^{\mathrm{d}}$. (C) Upper map, ${ }^{3} \mathrm{H}$-Arg-D ${ }^{\mathrm{dm} 1}$; lower map, ${ }^{14} \mathrm{C}$ Arg-D ${ }^{\mathrm{d}}$. 


\section{Discussion}

The initial goal of these studies was to characterize the structure of the $\mathrm{L}^{\mathrm{dm} 1}$ antigen of the $d \mathrm{ml}$ mutant mouse strain and to compare it with the structure of the $\mathrm{L}^{\mathrm{d}}$ antigen of the $d$ parental strain. These two molecules have been found to be highly homologous both in their overall biochemical characteristics and in their tryptic peptide compositions. Of their major Arg and Lys tryptic peptides, approximately 80 percent appear to be identical in these two molecules and it is thus concluded that the $\mathrm{L}^{\mathrm{dm} 1}$ amino-acid sequence will have relatively few amino-acid substitutions when compared with the $\mathrm{L}^{\mathrm{d}}$ amino-acid sequence now partially determined (Coligan et al. 1980). This level of peptide homology falls between that detected in the comparisons of $K^{b}$ mutants with the standard molecule (Nathenson et al. 1978, Nisizawa et al. 1981, Ewenstein et al. 1980, see Nairn et al. 1980b for a review) and that found in the comparison of $D^{\mathrm{dm} 1}$ with $\mathrm{D}^{\mathrm{d}}$ (Brown et al. 1978).

A plausible explanation for the structural differences found between $L^{\mathrm{dm} 1}$ and $L^{\mathrm{d}}$ is that the genetic event(s) which gave rise to the $d m 1$ mutant phenotype resulted in an alteration in the $L$-gene product. Our data, however, do not indicate whether or not the parent B10.D2 mouse - which Egorov (1967) subjected to treatment with the mutagen, diethyl sulfate, and which, when mated, gave rise to the (B10.D2 $\times$ C57BL/10Sn)F ${ }_{1}, d m 1$ mutant mouse (see Kohn et al. 1978, Nairn et al. 1980b) -already harbored an independently derived spontaneous mutation in the germline $L$ gene.

The gp $39^{\mathrm{dm} 1}$ antigen discovered in this investigation is judged to be a $d m 1$ mutant product because it has no evident counterpart in anti-H-2." 28 " immunoprecipitates of parental $d$ extracts. Coimmunoprecipitation of $\mathrm{gp} 39^{\mathrm{dm} 1}$ with $\mathrm{L}^{\mathrm{dm} 1}$ could be due to the presence of H-2.28 determinants on both molecules and/or an association between the two. Compositionally, gp $39^{\mathrm{dm} 1}$ appears to be deficient in Lys and Arg residues in comparison to $\mathrm{L}^{\mathrm{dm} 1}$ since it is barely detectable in immunoprecipitates of Lys-labeled $d m 1$ glycoprotein extracts and since it is lacking many of the Arg tryptic peptides of the $\mathrm{L}^{\mathrm{dm} 1}$ antigen. The gp $39^{\mathrm{dm} 1}$ antigen has at least two, and very possibly more, unique Arg peptides indicating that it is not a simple proteolytic fragment of $\mathrm{L}^{\mathrm{dm} 1}$, as we first assumed it to be, because one would have expected that all, or all but one, of its Arg peptides would correspond to Arg peptides of $L^{\mathrm{dm} 1}$. The molecular weight difference between these two molecules, which corresponds to approximately 55 amino acids, seems disproportionately small to account for the relatively extensive compositional differences in their Lys residues (see Fig. 1) and Arg peptides (see Fig. 4). If $g p 39^{\mathrm{dm} 1}$ is derived from $\mathrm{L}^{\mathrm{dm} 1}$ by proteolysis, $\mathrm{L}^{\mathrm{dm} 1}$ would have to have multiple, closely spaced proteolytic cleavage sites giving rise to slightly different $\mathrm{gp} 39^{\mathrm{dm} 1}$ products resulting in more than one new Arg tryptic peptide. Moreover, proteolysis of $\mathrm{L}^{\mathrm{dm} 1}$ to the $\mathrm{gp} 39^{\mathrm{dm} 1}$ form would have to be accompanied by the loss of at least six major and several minor Arg peptide peaks as well as the loss of the majority of the $\mathrm{L}^{\mathrm{dm} 1}$ Lys residues (unless the extent of proteolysis happened to be low in the two Lys-labeled preparations but relatively high in the three Arg-labeled preparations examined in this study). Although we cannot completely rule out the possibility that gp $39^{\mathrm{dm} 1}$ is derived by proteolysis from $\mathrm{L}^{\mathrm{dm} 1}$, our data suggest that this is a mutant gene product of a different origin. 
The $\mathrm{D}^{\mathrm{dm} 1}$ antigen structure is also unusual. As first shown by Brown and coworkers (1978), $\mathrm{D}^{\mathrm{dm} 1}$ is a "mosaic" structure in that most of its Arg tryptic peptides appear identical to the Arg peptides of the parental $D^{d}$ antigen, whereas most of its Lys tryptic peptides appear different from the parental Lys peptides. Our data, derived from experiments using a similar ion-exchange resin, confirm these observations and further suggest that $\mathrm{D}^{\mathrm{dm} 1}$ is like a D/L-hybrid structure in which at least five of its Lys peptides and three of its Arg peptides are identical to $L^{\mathrm{d}}$ and $\mathrm{L}^{\mathrm{dm} 1}$ peptides and different from $\mathrm{D}^{\mathrm{d}}$ peptides. Considering that the elution properties of peptides from the ion-exchange resin are extremely sensitive to subtle structural differences, we consider it improbable that eight new $\mathrm{D}^{\mathrm{dm} 1}$ tryptic peptides, not shared with $\mathrm{D}^{\mathrm{d}}$, would appear to match the positions and relative proportions of $L^{d}$ and $L^{d m 1}$ peptides purely by chance. However, it is still possible that some or all of these matched peptides could have different amino-acid sequences. It is reasoned that if a D/L-hybrid does exist, $\mathrm{D}^{\mathrm{dm} 1}$ and $\mathrm{D}^{\mathrm{d}}$ will probably have very similar $\mathrm{N}$-terminal sequences and that the $\mathrm{L}^{\mathrm{d}}$-like sequences in $\mathrm{D}^{\mathrm{dm} 1}$ are probably internal, nearer the $C$ terminus, because (1) the $\mathrm{N}$-terminal 125 amino acids of the $\mathrm{D}^{\mathrm{d}}$ molecule contain $15 \mathrm{Arg}$ and just one Lys amino-acid residue (Nairn et al. 1981); (2) the $\mathrm{D}^{\mathrm{d}}$ and $\mathrm{D}^{\mathrm{dm} 1}$ Arg-peptide profiles are 86 percent homologous (see above); and (3) the degree of $\mathrm{D}^{\mathrm{dm} 1}: \mathrm{L}^{\mathrm{d}}$ homology is greater between Lys-containing than between Arg-containing tryptic peptides.

One interpretation of these observations is that the $d m 1$ mutational event(s) has created a reorganization of $D$ and $L$ coding regions which is either real-e.g., a DNA rearrangement-or apparent-e.g., the result of aberrant processing of these regions. Unfortunately our knowledge of the organization and expression of MHC gene products in general is too limited at this time to allow an adequate molecular description of the $d m 1$ mutant genotype or even to suggest very likely alternative possibilities. Our data do suggest, however, that a special relationship exists in the $d m 1$ mutant between the $D$ and $L$ genes and possibly other $D / L$-linked genes.

Acknowledgments. We thank Samuel Young and Katherine Puckett for their excellent assistance in this study. Special gratitude is extended to Charles Ewing for designing the electronics and software for the computer graphics employed in this study. This work was supported by grants CA 24433-03 (DWS), AI 07289 (SGN), and AI 10702 (SGN) awarded by the Department of Health, Education and Welfare; and also by a National Multiple Sclerosis Fellowship, FG-490-A-1 (RN).

\section{References}

Brown, J. L., Kato, K., Silver, J., and Nathenson, S. G.: Notable diversity in peptide composition of murine $\mathrm{H}-2 \mathrm{~K}$ and $\mathrm{H}-2 \mathrm{D}$ alloantigens. Biochemistry 13: 3174-3178, 1974

Brown, J. L., Nairn, R., and Nathenson, S. G.: Structural differences between the mouse H-2D products of the mutant B10.D2.M504 $\left(H-2^{d a}\right)$ and the parental nonmutant strain B10.D2 $\left(H-2^{d}\right)$. J. Immunol. 120: $726-733,1978$

Coligan, J. E., Kindt, T. J., Nairn, R., Nathenson, S. G., Sachs, D. H., and Hansen, T. H.: Primary structural studies of an $\mathrm{H}-2 \mathrm{~L}$ molecule confirm that it is a unique gene product with homology to H-2K and H-2D antigens. Proc. Natl. Acad. Sci. U.S.A. 77: 1134-1138, 1980

Cullen, S. E., Freed, J. H., and Nathenson, S. G.: Structural and serological properties of murine Ia alloantigens. Transplant. Rev. 30: 236-270, 1976

Démant, P. and Néauport-Sautês, C.: The $H-2 L$ locus and the system of $\mathrm{H}-2$ specificities. Immunogenetics $7: 295-311,1978$ 
Ewenstein, B. M., Uehara, H., Nisizawa, T., Melvold, R. W., Kohn, H. I., and Nathenson, S. G.: Biochemical studies on the $\mathrm{H}-2 \mathrm{~K}$ antigens of the MHC mutants bm 3 and bm11. Immunogenetics 11: 383-395, 1980

Egorov, I. K.: A mutation of the histocompatibility-2 locus in the mouse. Genetika 3: 136-144, 1967

Gates, F. T., Coligan, J. E., and Kindt, T. J.: Complete amino acid sequence of murine $\beta_{2}$-microglobulin: Structural evidence for strain-related polymorphism. Proc. Natl. Acad. Sci. U.S.A. 78:554-558, 1981

Huang, C-M., Huang, H-J. S., and Klein, J.: Serology and polymorphism of $H$-2L-locus encoded antigens. Immunogenetics 9: 173-182, 1979

Iványi, D. and Démant, P.: Complex genetic effect of B10.D2 (M504) (H-2 $\left.{ }^{\mathrm{dm}_{1}}\right)$ mutation. Immunogenetics $8: 539-550,1979$

Klein, J.: $H-2$ mutations: Their genetics and effect on immune functions. Adv. Immunol. 26: 55-146, 1978

Klein, J.: The major histocompatibility complex of the mouse. Science 203: 516-521, 1979

Kohn, H. I., Klein, J., Melvold, R. W., Nathenson, S. G., Pious, D., and Shreffler, D. C.: The first $H-2$ mutant workshop. Immunogenetics 7: 279-294, 1978

Laemmli, U. K., and Favre, M.: Maturation of the head of bacteriophage T4. DNA packaging events. $J$. Mol. Biol. 80: 575-599, 1973

Levy, R. B. and Hansen, T. H.: Functional studies of the products of the $H-2 L$ locus. Immunogenetics 10 : $7-17,1980$

Michaelson, J., Rothenberg, E., and Boyse, E. A.: Genetic polymorphism of murine $\beta_{2}$-microglobulin detected biochemically. Immunogenetics 11: 93-95, 1980

Morgan, G. M., McKenzie, I. F. C., and Melvold, R. W.: The relationship between the $H$-2 loss mutations of $H-2^{d a}$ and $H-2^{d b}$ in the mouse. Immunogenetics 7: 247-258, 1978

Nairn, R., Nathenson, S. G., and Coligan, J. E.: Isolation, characterization and amino acid sequence studies of the cyanogen bromide fragments of the H-2D ${ }^{\mathrm{d}}$ glycoprotein. Eur. J. Immunol. 10: 495-503, 1980a

Nairn, R., Yamaga, K., and Nathenson, S. G.: Biochemistry of the gene products from murine MHC mutants. Annu. Rev. Genet. 14:241-277, 1980b

Nairn, R., Nathenson, S. G., and Coligan, J. E.: Amino acid sequence of $\mathrm{CNBr}$ fragment $\mathrm{CN}-\mathrm{C}$ (residues 24-98) of the mouse histocompatibility antigen $\mathrm{H}-2 \mathrm{D}^{\mathrm{d}}$ : A comparison of the $\mathrm{NH}_{2}$-terminal 100 residues of $\mathrm{H}-2 \mathrm{D}^{\mathrm{d}}, \mathrm{D}^{\mathrm{b}}, \mathrm{K}^{\mathrm{d}}$ and $\mathrm{K}^{\mathrm{b}}$ reveals discrete areas of diversity. Biochemistry, in press, 1981

Nathenson, S. G., Ewenstein, B. M., Brown, J. L., Nisizawa, T., Uehara, H., and Sears, D. W.: The structural-genetic relationships of the $\mathrm{H}-2 \mathrm{~K}$ and $\mathrm{H}-2 \mathrm{D}$ products of the mouse major histocompatibility complex. In R. A. Lerner and D. Bergsma (eds.): Birth Defects: Original Article Series, Volume 14, p. 566, Alan R. Liss, New York, 1978

Natori, T., Katagiri, M., Tanigaki, N., and Pressman, D.: The 11,000-dalton component of mouse H-2. Isolation and identification. Transplantation 18: 550-555, 1974

Nisizawa, T., Ewenstein, B. M., Uehara, H., McGovern, D., and Nathenson, S. G.: Biochemical studies on the H-2K Antigens of the MHC Mutant bm1. Immunogenetics 12: 33-44, 1981

Robinson, P. J., Graf, L., and Sege, K.: Two allelic forms of mouse $\beta_{2}$-microglobulin. Proc. Natl. Acad. Sci. U.S.A. $78: 1167-1170,1981$

Sears, D. W. and Polizzi, C. M.: Biochemical evidence for a separate, $M H C$-linked locus encoding H-2.28 antigens. Immunogenetics 10:67-82,1980

Sears, D. W. and Wilson, P. H.: Biochemical evidence for structurally distinct $\mathrm{H}-2 \mathrm{D}^{\mathrm{d}}$ antigens differing in serological properties. Immunogenetics 13: 275-284, 1981

Sears, D. W., Young, S., Wilson, P. H., and Christiaansen, J. E.: Structual characterization of H-2L alloantigens. I. Complete tryptic peptide analysis of H-2L ${ }^{\mathrm{a}}$. J. Immunol. 124: 2641-2649, 1980 